\title{
(2483) Proposal to conserve the name Scilla (Hyacinthaceae) with a conserved type
}

\author{
Mario Martínez-Azorín \& Manuel B. Crespo \\ dCARN (Depto. de Ciencias Ambientales y Recursos Naturales) \& CIBIO (Instituto de la Biodiversidad), Universidad de Alicante, \\ P.O. Box 99, 03080 Alicante, Spain \\ Author for correspondence: Mario Martínez-Azorin, mmartinez@ua.es
}

DOI https://doi.org/10.12705/656.19

(2483) Scilla L., Sp. Pl.: 308.1 Mai 1753 [Lil. / Asparag.], nom. cons. prop.

Typus: S. bifolia L., typ. cons. prop.

Linnaeus (Sp. Pl.: 308. 1753) described Scilla to include eight species from the Mediterranean basin, Europe and SW Asia. This generic concept included a considerable variation in reproductive and vegetative characters. Subsequent authors restricted the Linnaean concept of the genus, and more recently Speta (in Phyton (Horn) 38: 1-141. Aug 1998; in Kubitzki, Fam. Gen. Vasc. Pl. 3: 261-285. 1998; in Stapfia 75: 139-176. 2001), based on morphological and molecular studies, placed the Linnaean species of Scilla in eight different genera belonging to three different subfamilies of Hyacinthaceae (vide Pfosser \& Speta in Ann. Missouri Bot. Gard. 86: 852-875. 1999; Manning $\&$ al. in Edinburgh J. Bot. 60: 533-568. 2004). These subfamilies are currently widely accepted on the basis of clear morphological, molecular and biogeographic evidences. Of those eight genera recognized by Speta, Cathissa Salisb. (including S. unifolia L.) belongs to Hyacinthaceae subfam. Ornithogaloideae Speta; Charybdis Speta (including S. maritima L.) belongs to Hyacinthaceae subfam. Urgineoideae Speta; and the remaining genera, Hyacinthoides Heist. ex Fabr. (including $S$. italica L.), Oncostema Raf. (including S. peruviana L.), Othocallis Salisb. (including S. amoena L.), Prospero Salisb. (including S. autumnalis L.), Scilla L. (including S. bifolia L.) and Tractema
Raf. (including S. lilio-hyacinthus L.) belong to Hyacinthaceae subfam. Hyacinthoideae Link. Alternatively, Hyacinthaceae are treated as Asparagaceae subfam. Scilloideae Burnett (e.g., by Chase \& al. in Bot. J. Linn. Soc. 161: 135. 2009), and the subfamilies above are then reduced to the tribes Ornithogaleae Rouy, Urgineeae Rouy and Hyacintheae Dumort., although we favour the familial treatment. This large group of plants includes threatened species listed for conservation, and also widely cultivated plants with ornamental and medicinal value and high economic impact worldwide.

Lectotypification of Scilla has been widely attributed to Hitchcock (in Sprague, Nom. Prop. Brit. Bot.: 146. Aug 1929) on Scilla bifolia L. (vide Index Nominum Genericorum, 2016: http:// botany.si.edu/ing/; Speta, 1.c., 1998: 121). In this way, Scilla L. (s.str.) is applied to plants of Hyacinthaceae subfam. Hyacinthoideae with bracts minute or absent, no bracteoles, blue perigone segments (from almost free to fused up to $40 \%$ of their length), blue, ovoid ovary, and globose seeds with an elaiosome (Speta, 1.c. 1998; Speta in Kubitzki, 1.c.) and includes as synonyms the generic names Genlisa Raf. (Autik. Bot.: 57. 1840), Adenoscilla Gren. \& Godr. (Fl. France 3: 187. ante Jun 1855), Rinopodium Salisb. (Gen. Pl.: 28. Apr-Mai 1866), all with S. bifolia as type, and Chionodoxa Boiss. (Diagn. Pl. Orient. ser. 1(5): 61. Oct-Nov 1844), with S. luciliae (Boiss.) Speta as type. It is worth mentioning that the earliest of these, Genlisa Raf., typified by Pennell (in Bull. Torrey Bot. Club 48: 93. 8 Mar 1921), has two 
earlier parahomonyms, Genlisia Rchb. (Consp. Regn. Veg.: 60. Dec 1828-Mar 1829), an illegitimate name, and Genlisea A. St.-Hil. (Voy. Distr. Diam. 2: 428. 1833), a name in current use. No recommendation exists on whether these names should be treated as homonyms and parallels are ambiguous (McNeill in Taxon 63: 950-951. 2014).

Rafinesque (Fl. Tellur. 2: 13. Jan-Mar 1837) had previously published "Skilla" as what he considered the orthographically correct spelling for Scilla L. as follows: "13. Skilla L. mispelt Scilla. char vere. Petalis 6 sessilis planis, patulis caducis, Stam. 6 oppos. filiformis. stylo filif. stigma simplex. caps. 3 loc. polysp-Type Sk. maritima and all the sp. with filiform filaments as stated by L. but many sp. united that lack this good character." As Rafinesque (1.c. Jan-Mar 1837: 13) indicated more than one species as "Type", this is not an effective typification under Art. 10 of the ICN (McNeill \& al. in Regnum Veg. 154. 2012). However, later, in the Preamble to volume 3 of the same work, Rafinesque (1.c. 3: 8. Nov-Dec 1837) wrote "since Skilla maritima type of Skilla has white flowers!". Thus Rafinesque explicitly cited Scilla maritima as type of the Linnaean generic name, a designation much earlier than Hitchcock's and one that must therefore be followed (Art. 10.5 of the $I C N$ ). This fact has important nomenclatural consequences affecting two generic names included in two different subfamilies, the name of one of those subfamilies, and also that of a tribe for those who place these species in Asparagaceae s.l.

Now included within Hyacinthaceae subfam. Urgineoideae, which is generally characterised by the bracts being spurred, at least the basal ones, the genus Urginea was described by Steinheil (in Ann. Sci. Nat., Bot., sér. 2, 1: 322, t. 14. 1834) to include species previously placed in Scilla, including Scilla maritima L. (as U. scilla Steinh.) and six other species with variable morphology and distribution, currently placed in Tenicroa Raf., Urginea Steinh. and Charybdis Speta. Soon after his description of Urginea, Steinheil (in Ann. Sci. Nat., Bot., sér. 2, 6: 276. 1836) described the genus Squilla Steinh. to segregate Scilla maritima $(\equiv U$. scilla) from Urginea. He justified morphologically and orthographically this new segregation from other apparently allied groups such as Ornithogalum L., Stellaris Fabr. and Scilla L. (pro parte). Based on morphological and molecular studies, Speta (1.c., 1998: 58) published the new name Charybdis Speta to replace Squilla Steinh., since he considered the latter to be a mere orthographic variant of Scilla L. ('Skilla Raf.', orth. var.), and therefore a later illegitimate homonym. The species of Charybdis form a monophyletic group with a distinct morphology and biogeography that supports its acceptance as a good genus, as has become the case in the last decades by many authors working on Hyacinthaceae (cf. Speta, 1.c. 1998: 58; Conti \& al., Annot. Checkl. Italian Vasc. Fl.: 77. 2005; Bacchetta \& al. in Phytotaxa 69: 16-26. 2012; Ali \& al. in J. Integr. P1. Biol. 55: 950 964. 2013), although others (e.g., Manning \& al., 1.c.) include them in an expanded Drimia Jacq. ex Willd. (Sp. Pl. 2: 165. 1799). However, even if Speta's view, not shared by its author Steinheil, that Squilla should be treated as a homonym of Scilla is accepted, Charybdis is still an illegitimate name under Art. 52 as it was superfluous when published, its type being Rafinesque's previously designated type of Scilla L., a typification that was probably unknown to Speta (1.c. 1998: 58). This makes Charybdis unavailable for use regardless of the outcome of this conservation proposal. Martínez-Azorín \& Crespo (in Taxon 65: 1437-1438. 2016) have requested a binding decision as to whether or not Scilla L. and Squilla Steinh. should be considered sufficiently alike to be confused. Under the current typification of Scilla this is unimportant, as it would merely determine whether Squilla was an orthographic variant or an illegitimate replacement name for Scilla. However, if this conservation proposal is accepted, treating Squilla as not confusable with Scilla will leave the former name usable for the current concept of Charybdis.

Having to accept Rafinesque's (1.c. Nov-Dec 1837) first typification of Scilla L. by S. maritima L. threatens the nomenclatural stability not only of two widely used generic names but also the application of the name tribus Scilleae Bartl. (Ord. Nat. Pl.: 50. Sep 1830), which would replace tribus Urgineeae Rouy (Fl. France 12: 330, 424. Nov 1910), currently in use in Asparagaceae. Furthermore, Scilla (s.str.) would be applied to those species of Hyacinthaceae subfam. Urgineoideae (which would become subfam. Scilloideae) currently placed in Charybdis, the latter including about 10 taxa that would require transfer to the generic name Scilla in its "new" circumscription. For those, such as Manning \& al. (1.c.), who include almost all the subfamily Urgineoideae in Drimia, all 100 or so species would have to be transferred to Scilla.

Perhaps even more serious, the traditional and widely used generic name Scilla (as typified by $S$. bifolia, belonging to subfam. Hyacinthoideae), includes in a wide sense around 80 species (The Plant List, 2016: http://www.theplantlist.org/tpl1.1/search?q=Scilla) or, in a more restricted concept, 30 species (Speta, 1.c. 1998: 1-141), and all would require relocation and new combinations, either in Genlisa or Chionodoxa, depending on whether or not the former is considered confusable with its parahomonyms.

In summary, following Rafinesque's typification, the well-established name Scilla will have to be applied in a sense that is contrary to its traditional usage, and applied to plants currently placed in a different subfamily. Furthermore, the current Asparagaceae tribus Urgineeae would be replaced by Asparagaceae tribus Scilleae, currently a synonym of Asparagaceae tribus Hyacintheae. This solution would not favour the goal of nomenclatural stability enunciated in the Melbourne Code; certainly, it would create unnecessary instability for the names of a subfamily or of a tribe, depending on family delimitation, and of two genera currently well-established and with high economic importance. To avoid this, we formally propose to conserve Scilla with a conserved type (Art. 14.9 of the ICN), following Hitchcock's (1.c.) typification on Scilla bifolia L., which will maintain current usage of Scilla. Unfortunately, the quite recently published Charybdis is unavailable for use without conservation, but, depending on the outcome of the parallel request for a binding decision, the name Squilla may be available for the species included in it. Acceptance of the present proposal will surely minimize future confusion for taxonomists, conservationists and horticulturists.

\section{Acknowledgements}

We thank John McNeill and John Wiersema for their comments on the early version of the manuscript and nomenclatural advice. This work was partly supported by H2020 Research and Innovation Staff Exchange Programme of the European Commission, project 645636: "Insect-plant relationships: insights into biodiversity and new applications" (FlyHigh). 